\title{
P6 CFD Modelling of Arterialized Venous Flap
}

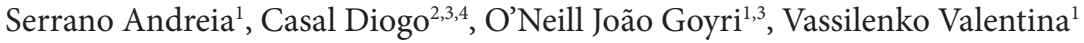 \\ ${ }^{1}$ Laboratory of Instrumentation, Biomedical Engineering and Radiation Physics (LIBPHYS), \\ NOVA School of Science and Technology - NOVA University Lisbon, Portugal \\ ${ }^{2}$ Plastic and Reconstructive Surgery Department and Burn Unit; Centro Hospitalar de Lisboa Central, Lisbon, Portugal \\ ${ }^{3}$ Anatomy Department, Nova Medical School, NOVA University of Lisbon, Lisboa, Portugal \\ ${ }^{4}$ Centre for Chronic Diseases (CEDOC); NOVA Medical School, Lisbon, Portugal
}

\section{ABSTRACT}

The knowledge about the required quantity of blood to irrigate an angiosome is important on ischemia (disruption on blood perfusion) prediction, diagnosis and treatment. An angiosome (or flap) is an anatomic unity (or flap) of tissue, it is constituted by skin, subcutaneous tissue and muscle, it is irrigated by an artery and drain by specific veins [1]. Since 70's, flaps have been used on clinical practice for reconstruction of complex anatomical structures. Different model configurations have been created, to find a flap's model that allows a better flap perfusion. In previous work [2] the four models with an average flap survival area of $76.86 \% \pm 13.67 \%$ were tested in 53 male rats: I - conventional model of flap's blood supply formed by femoral and epigastric arteries; II - Arterialized Venous Flap (AVF) produced by femoral side-to-side anastomosis; III - AVF produced by femoral side-to-side anastomosis and proximal ligation of the femoral vein; IV - AVF produced by terminal lateral anastomosis of the epigastric vein to the femoral artery). The experimental results have shown that the AVFs in group IV represent an optimized model of unconventional perfusion flap. In the present work the Computational Fluid Dynamics (CFD) methods, an ANSYS ${ }^{\circ}$-Fluent code, were used for simulating a blood flow and flap perfusion in AVFs of group IV in order to find an optimum geometry for lateral anastomosis of the epigastric vein to the femoral artery with an angle variation from $90,0^{\circ}$ to $45,0^{\circ}$. We find that the optimum angle is $86,5^{\circ}$. Three other models, conventional and unconventional, was also tested by CFD, finding that unconventional AVF of group III provides a greater blood flow through the epigastric vein, allowing a better perfusion of the flap.

\section{REFERENCES}

[1] Casal D, Pais D, Iria I, Mota-Silva E, Almeida MA, Alves S, et al. A model of free tissue transfer: the rat epigastric free flap. J Vis Exp 2017;119:14-16.

[2] Casal D, Mota-Silva E, Pais D, Iria I, Videira PA, Tanganho D, et al. Optimization of an arterialized venous fasciocutaneous flap in the abdomen of the rat. Plast Reconstr Surg Glob Open 2017;5:e1436.

(c) 2019 Association for Research into Arterial Structure and Physiology. Publishing services by Atlantis Press International B.V. This is an open access article distributed under the CC BY-NC 4.0 license (http://creativecommons.org/licenses/by-nc/4.0/). 